\title{
WORDUP MOBILE APPLICATION - AN ENTERTAINING FORM OF PERFECTING YOUR ENGLISH VOCABULARY
}

\author{
Neda Maenza*, \\ Tijana Gajić
}

Faculty of Informatics and Computing, Singidunum University,

Belgrade, Serbia

\begin{abstract}
:
Combining innovative ideas with the latest digital technology has enabled learners worldwide to perfect their English in a revolutionary way. This paper presents WordUp mobile application for learning new English words and improving vocabulary. This app has succeeded in ranking all the words in the English language in order of how useful they are. WordUp first detects knowledge gaps and then creates a personalized learning plan that focuses on one word at a time, always ensuring that most useful word is being learnt first. The aim of this paper is to examine students' views on the usefulness of this app. In accordance with the set goals and hypotheses, the qualitative research, in the form of a focus group, has been conducted on a representative sample of the student population of Singidunum University in Belgrade. The study results confirmed that students want to learn English vocabulary in an innovative and fun way. Their enthusiasm leads the authors to believe that mobile applications for learning foreign languages should be introduced into curricula. An important finding of this study is that WordUp is quite often used instead of a dictionary. This app is suitable for all people willing to improve their English vocabulary in a flexible and dynamic way.
\end{abstract}

Keywords:

WordUp, mobile applications, foreign language learning, vocabulary acquisition.

\section{INTRODUCTION}

Vocabulary did not have a special status in teaching foreign languages until the Communicative Language Teaching or Communicative Approach has become extremely popular and used worldwide. Leading linguists and language teachers often disagree on formal instructions, strategies or methods that would be most effective for vocabulary acquisition. In recent years, the most significant progress in the study of vocabulary within applied linguistics has been the use of ComputerAssisted Corpus Analysis (CACA) [1]. In that way, an empirical basis for determining word characteristics was obtained, instead of simply relying on intuition [2]. Computer-Assisted Corpus Analysis is considered to be
Correspondence:

Neda Maenza

e-mail:

nmaenza@singidunum.ac.rs 
a revolutionary approach to teaching vocabulary. It has contributed to the development of modern dictionaries based on corpus data. CACA also enables us to determine lexical units frequency in both spoken and written language, as well as to obtain important information on phrases and collocations. Phrases and collocations are believed to be lexical patterns that native speakers adopt quite easily, while foreign language students still focus on learning individual words [2], although learning collocations is essential for making a foreign language sound fluent and natural [3]. The main source of language data is the corpus. A corpus is a collection of thousands of different 'texts' stored on a computer or in the cloud [4]. The point of using a corpus is that we can't observe all the English that is being used by millions of people all over the world, so instead we look at a representative sample of English texts by using intelligent digital tools. Corpus enables discovering the contexts in which words appear as well as identifying patterns and functions that are not obvious or are contrary to the intuition of a teacher or a textbook writer [5]. The data obtained from the corpus are the best indicators of the words frequency, as an important aspect of lexical processing [2]. In language, the more frequent something is, the more useful it is to learn. Based on the frequency, vocabulary lists are created in order to meet the teaching and certification requirements at certain levels in accordance with the Common European Framework of Reference for Languages [6].

Due to the tremendous development of IT sector, Computer-Assisted Language Learning (CALL) has become E-learning, Distance Learning and Mobile Learning [7]. CALL requires students' digital competence. It is necessary to pay special attention to the concept of mobile learning due to the fact that children get their mobile phone quite early and young population increasingly use the available content [8]. The Millennial generation has grown up with digital devices, so mobile learning is tailored to the way they work and think. Easy accessibility is one of the most important aspects of m-learning. Additionally, m-learning enables learners to take their learning materials with them. Mobile applications for learning foreign languages play an important part within it.

\section{WORDUP MOBILE APPLICATION}

Word Up is a revolutionary mobile application for learning new English words and improving vocabulary. It is completely different from all other mobile appli- cations aimed at foreign language learning. The main goal is to combine innovative ideas with the latest digital technology, in order to facilitate the language challenges people all around the world regularly face. The philanthropic vision of the application creators is to help everyone who wants to improve their English vocabulary, both productive and receptive, without financial compensation, in an innovative and modern way [9].

It is important to emphasise the fact that WordUp app has ranked all the words in the English language in order of how useful they are by using Computer-Assisted Corpus Analysis. Therefore, every user makes the most of their learning time because they focus on what matters the most.

This mobile application analyses millions of movies, TV shows, songs, stories, newspaper articles, famous people's quotes and similar captivating material in order to bring the most helpful, exciting and enjoyable examples for each word to its users. One of the main objectives is to learn in context; in other words, to learn how to use each word in real life, while truly enjoying the process of learning.

One of the main principles of this mobile app is " $r$ member forever". When a user learns a new word, the next day the app will check if the user remembers it. If not, the user sees the explanation, examples or translation in order to practice again. The users can also practice pronounciation (it is possible to choose between British and American English). This repeats until one day the user says "I remember". Then it comes back in 3 days. If the user still remembers the word or phrase, it comes up in 7 days, then a month, then 3 months and finally after a year. According to WordUp, if the user remembers the word or phrase after a year, they have learnt it for life.

One of the features that make this application so special is personalisation. WordUp first detects where the gaps in users' knowledge are and then creates a personalised learning plan that focuses on one word at a time, always ensuring that the users learn the most useful word first.

WordUp is designed to become a part of users' lives, supporting them every day. Once the map of their knowledge gaps is created, the users will start to fill the gaps. They begin to follow a plan while learning new words and phrases.

WordUp can be one of the best pastime activities. Rather than wasting time on social media, learners can consume entertaining news and other content that WordUp will gather for them, all while improving their knowledge in a relaxed fashion [9]. 


\section{STUDY AIMS AND HYPOTHESES}

The aim of this paper is to determine students' views on WordUp mobile application and its usefulness. Before conducting the research, the following hypotheses were set:

- Students who use WordUp mobile application prefer/enjoy personalized learning plan and the fact that WordUp has ranked all the words in the English language in order of how useful they are.

- Students find learning in context the most helpful option (users are offered movies, TV shows, songs, stories, newspaper articles, famous people's quotes etc.).

- Students, due to their faculty obligations, are not ready to spend much time using this mobile application on a daily basis, but they would strongly support this app to be introduced into their curriculum.

\section{RESPONDENTS}

The respondents are Singidunum University students who voluntarily agreed to participate in this research. They are fourth-year students of the Faculty of Informatics and Computing and the Faculty of Tourism and Hospitality Management, as well as second-year students of the Faculty of Business in Belgrade. Qualitative research, in the form of a focus group, was conducted in order to determine the clearest possible picture of students' views concerning WordUp mobile application and possible ways to improve the English language vocabulary. Six students who have used and/or still use this mobile application participated in qualitative research; therefore, their opinion can be considered relevant. It should be noted that this is a deliberate, not a simple random sample, since selected students are communicative, open-minded, extroverted and quite motivated to learn foreign languages according to data from practice (active participation in the learning process and extracurricular activities at the university). Students, participants in the focus group, previously filled out an online survey and thus participated in the quantitative part of the study on modern trends in learning English and improving its vocabulary by using WordUp mobile app, which was part of our previous research [10]. We opted for qualitative research considering it more suitable for expressing attitudes and describing experiences.

\section{RESEARCH QUESTIONS}

Our study was guided by the following questions:

- Have you ever used/Do you use WordUp mobile app?

- Has this app helped you improve your English language skills? When did you find it most useful?

- When introducing a new word, which option helps you the most?

- What do you like most about WordUp and what distinguishes it from all other language applications?

- List the benefits/advantages of WordUp.

- List the disadvantages/shortcomings of WordUp.

- How much time a day do you spend using this app?

- At what times of the day do you use this app?

- Would you recommend this app to others? Why?

- Would you like this application to be used as part of regular classes or as homework?

\section{RESEARCH RESULTS}

When asked whether they used/use WordUp mobile application, five out of six respondents answered in the affirmative. Most of them continued to use it on a regular basis, stating that this app is more reliable than all the others, and above all, it is useful, efficient and easy to use.

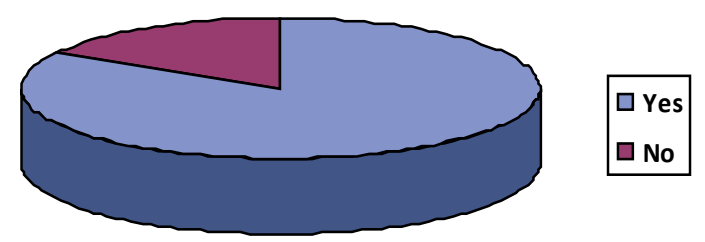

Fig. 1. Have you used/Do you use WordUp?

One respondent finds this application to be particularly useful during English classes; she points out the importance of "learning in context" concept - by using "Search" option she manages not only to check the meaning of a word or phrase but also real life situation examples such as short movie inserts, newspaper articles, popular songs etc. The rest of the group completely agreed with her. 
Respondents stated various advantages of WordUp app such as easy word/phrase memorization strategies, word families and parts of speech explanations. Also, it is confirmed that this application is great for filling knowledge gaps. Moreover, it proves to be great additional tool to stay in daily contact with the English language. Words and phrases are presented visually as well, through photos and pictures, which is particularly suitable for visual types of people. Visual representations of words through photographs and pictures is particularly emphasized in relation to easier memorization of new words and phrases. One of the students stated that this app is aimed only at learning the English language which is one of its biggest disadvantages. She adds that, due to the fact that English is a global language and ,everyone speaks English", it would be more useful to learn other languages, such as French, German or Spanish in the same way.

The question „Has this app helped you improve your English language skills? When did you find it most useful?" proved to be really interesting one. One student said that the language progress was evident and the app especially helped her in improving her speaking skills. While listening to series and movies inserts and popular songs lyrics, she repeated the words, remembered them far easier than before and found it much more entertaining. Another student claimed that this application helped her improve her listening skills. There is also an important observation regarding all the functions of the app which was particularly emphasized by our students. WordUp ranked all the words in the English language in order of how useful and complex they are, always ensuring users learn the most useful (and the simplest) word first. Additionally, WordUp helps the users assess their vocabulary and helps them learn new and useful words in each lesson, starting from simple to really complex ones. Users can choose between English for Specific Purposes and English for Academic Purposes. One of the students believes to be proficient English speaker but he does not prefer learning ESP and EAP because he does not think he will ever be in a position to use those words/phrases. He adds that „those phrases are just for experts to use“. Talking generally about language mobile applications, one of the students claimed he saw no significant progress regarding all language skills. Although he considered mobile apps an excellent additional educational tool, he still preferred traditional teaching methods, class interaction and foreign language teachers to be irreplaceable.

When asked which option helped them the most when introducing a new word, vast majority of respondents said that it was the definition of words from the dictionary, as well as "learning in context" concept; students learn how to use words/phrases in real life situations by watching/listening to popular songs, movies and series inserts, newspaper articles, celebrities quotes etc. They particularly liked Test me! option because they could immediately check if they had memorized the word. Additionally, they liked visual presentation of the word. On the other hand, translation of the word into their mother tongue is of the least importance.

Students listed almost all the options that WordUp offers as their favorite ones when asked about the advantages of this app. In their opinion, the most important pros are as follows: personalized dictionary, knowledge map, personalized words ranking in order of how useful they are, regular reminders - users can choose the best time of the day for learning English (just woke up, around breakfast, way to work/school, around lunchtime, way back home, in bed), as well as the amount of time they dedicate to it, depending on the goals set (casual, regular, serious, champion). Category option is also emphasized as most useful one, according to the respondents. This option is usually used when preparing for the exam, as well as expanding vocabulary related to one's profession or specific category such as sport, family, furniture, fruit, cooking, arts, business etc. Respondents said they especially liked the Exam Preparation option, which helps the users familiarize with the format of the tests, questions and task types for each section (listening, reading, writing and speaking) So far, IELTS, TOEFL, PTE, GRE and SAT have been offered. The users can independently prepare for each of the tests mentioned by using WordUp mobile application. Furthermore, participants stated that this app offers extremely fun English learning. There are certain gamification elements and especially designed Word Games option. Subcategories Smart Eyes!, Said What?, Confuse me! and Spell It! in an entertaining way help users improve all their language skills. The respondents see games as a challenge, they hold their attention the most and they consider them meaningful in context of learning new words." Respondents also compared WordUp app and Google Translate favoring the first option due to possibilities of using a given word in various contexts instead of offering basic translation. In addition, when using WordUp as a dictionary, users can hear the pronunciation of the word either in American or British English; also, word definition, synonyms and sentence examples are immediately provided. All of the interviewed students agreed that the previously mentioned option was the most useful to them. 

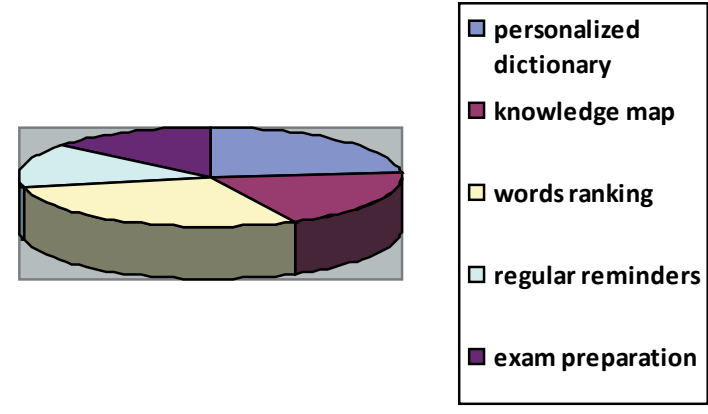

Fig. 2. Advantages of WordUp

After the detail analysis of all the answers, the main benefits of WordUp mobile application are believed to be:

- it is free and accessible

- it can serve as a pocket dictionary

- it can meet different demands.

The app is designed for various needs - all sorts of users can learn English vocabulary they personally need the most. One respondent even found this app more relevant and reliable than the most popular translation platform, Google Translate, and believed it should be included as one of the English dictionaries on Google Play Store. Respondents believe the advantage of the application is its wide range of topics, as well as "all possible categories of words". Furthermore, learning in context concept, knowledge gap detection and personalized learning plan are also strengths that make this application unique.

According to the respondents, technical problems are the main shortcomings of this application. It happens that the application "locks up and slows down" or fails to load or display images. They also believe that this is a young application and that lots of effort has been constantly put in order to improve it. One respondent states that the option of voice recording is missing - she would prefer searching the words by voice instead of writing them. Another participant states that the application sometimes offers a strange choice of words. Lack of communication with other people, the fact that the app is not as interesting and caring as a teacher and taking the app only as a game are also some of the most mentioned disadvantages; sometimes students feel they just improve vocabulary, not all language skills. A participant believes this application is not either aimed at beginners or at those who are fluent English speakers, but at those who are intermediate learners with the main goal of expanding their vocabulary.
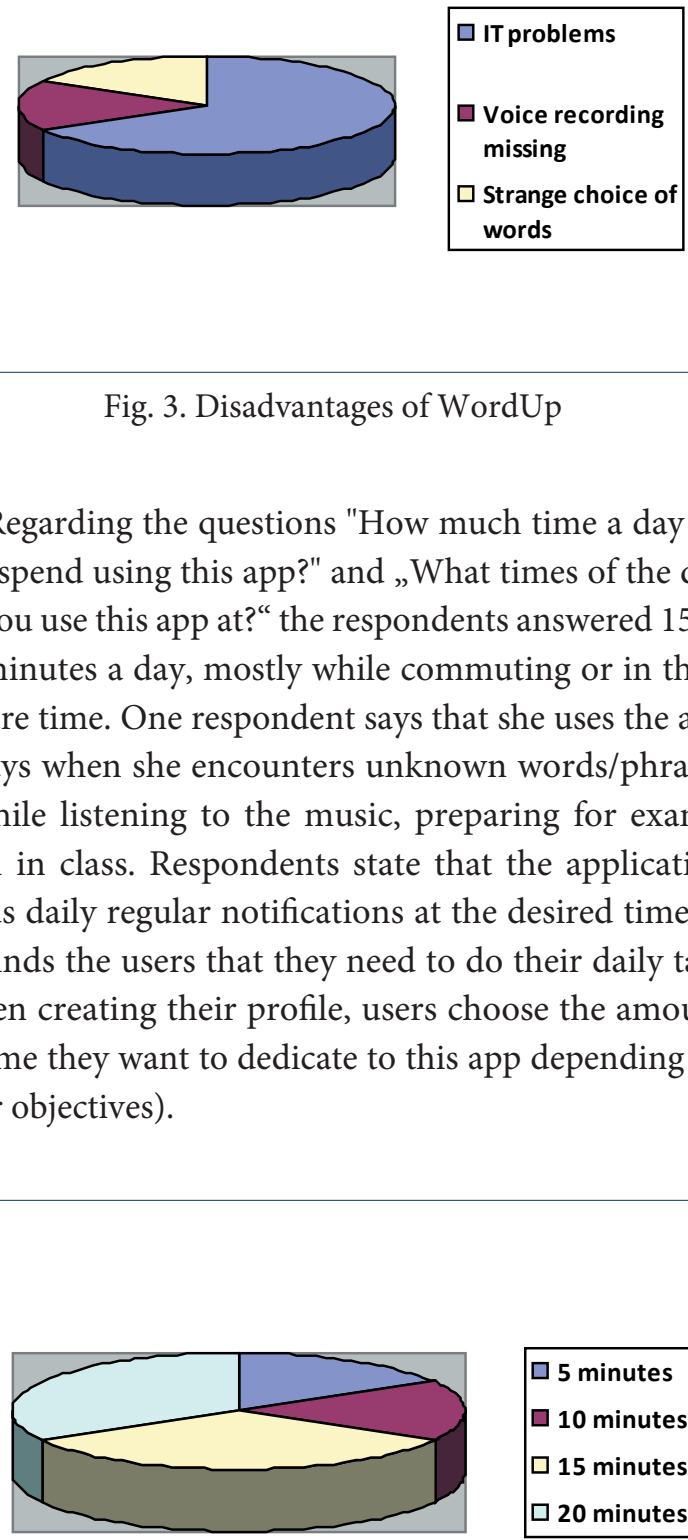

Fig. 3. Disadvantages of WordUp

Regarding the questions "How much time a day do you spend using this app?" and „What times of the day do you use this app at?" the respondents answered 15 to 20 minutes a day, mostly while commuting or in their leisure time. One respondent says that she uses the app always when she encounters unknown words/phrases - while listening to the music, preparing for exams, even in class. Respondents state that the application sends daily regular notifications at the desired time. It reminds the users that they need to do their daily task (when creating their profile, users choose the amount of time they want to dedicate to this app depending on their objectives).

Fig. 4. How much time a day do you spend using this app?

All participants unanimously said that they would recommend WordUp application as a dictionary and as a useful and modern digital tool for English language learning. They think it can be great pastime activity. Also, all respondents would like to see this app as part of their curriculum, either as icebreaker activity or homework. 


\section{CONCLUSION}

It is necessary to emphasize that the study presented in this paper is a small one. More precisely, the sample size is relatively small. One the other hand, bearing in mind that this is a qualitative analysis, sample size is large enough to obtain enough data to sufficiently describe the ways of improving English vocabulary and WordUp app usefulness. Hopefully, this study can be a solid starting point for more complex, practice-oriented educational research.

The research explicitly confirmed that the innovative ways of perfecting the English language, such as mobile applications designed to improve foreign language skills are captivating for students. Students consider mobile apps of this kind to be likeable and helpful so they would like to use them on a regular weekly basis as part of their curriculum. Also, they would enjoy using mobile apps independently in their leisure time. Respondents believe WordUp mobile app to be an effective educational tool that leads to certain learning progress of its users. One of the most important findings of this study is that WordUp is quite often used instead of a dictionary. Students find it reliable, interesting and accessible and prefer using it over standard online dictionaries or platforms.

In conclusion, WordUp mobile application is a great digital tool for improving English vocabulary in a modern, pleasant and fun way. Although students think this app is a great one, they are still in favor of traditional methods and approaches to learning foreign languages.

Students can easily perfect all their language skills by using this app on a regular basis. They can also significantly expand their vocabulary, study according to their personalized learning plan, achieve their academic goals and face specific language challenges.

We would recommend using WordUp on a daily basis to all people motivated to improve their language skills and expand their English vocabulary in an efficient, dynamic and flexible way. Users of this mobile application monitor their learning process and take responsibility for their own progress and ability to communicate effectively in English.

\section{REFERENCES}

[1] M. Stanojević Gocić, „Strategije učenja i usvajanja vokabulara u funkciji razvijanja veštine čitanja u nastavi engleskog jezika struke", doktorska disertacija, Kragujevac: Filološko-umetnički fakultet, 2017.

[2] N. Schmitt, Researching Vocabulary: A vocabulary research manual vocabulary in language teaching. New York: Palgrave Macmillan, 2010.

[3] B. Radić Bojanić, Vokabular u nastavi stranih jezika: budućnost ponikla u prošlosti, Savremena proučavanja jezika i književnosti, Zbornik radova sa I naučnog skupa mladih filologa Srbije, 439-451. Kragujevac: FILUM, 2009.

[4] Macmillan Dictionary. [Online]. Available: https:// www.macmillandictionary.com/corpus.html

[5] D. Nunan, Second language teaching and learning. Boston: Heinle \& Heinle, 1999.

[6] Common European Framework of Reference for Languages. [Online]. Available: https://www.coe. int/en/web/common-european-framework-reference-languages/level-descriptions

[7] C. Chaka, "Portable Handheld Language Learning from CALL, MALL to PALL", Handbook of Research on E-Learning Methodologies for Language Acquistion, Walter Sisulu University, South Africa, pp. 539-554. 2009.

[8] T. Gajić \& N. Maenza, „Korišćenje mobilnih aplikacija u nastavnom procesu učenja stranih jezika na tercijarnom obrazovnom nivou", Inovacije u nastavi, 32 (4), 133-142, 2019.

[9] WordUp: Discover \& Learn the most useful English word. [Online]. Available: https://www.wordupapp.co/

[10] N. Maenza \& T. Gajić, "Mobilna aplikacija WordUp - inovativno i zabavno usvajanje vokabulara engleskog jezika", Sinergija 2019 - zbornik radova, Bijeljina: Univerzitet Sinergija, 2019. 